\title{
A brief history of Aaron Swartz on GitHub
}

\author{
Camille Akmut
}

July 1, 2019

\begin{abstract}
This research covers the complete period from 2008, when Aaron Swartz first joined GitHub, to just a few days before his death in January 2013. It includes, where available, relevant entries from his blog for context (later entitled Raw thought) and other sources.
\end{abstract}




\section{Introduction}

Aaron Swartz created his account, aaronsw, on Github on April $42008^{1}$.

His first recorded major action was to create a repository called watchdog.

His first commit belonged to it.

He chose the following picture for his profile and never changed it - so far as we are able to tell' ${ }^{2}$.

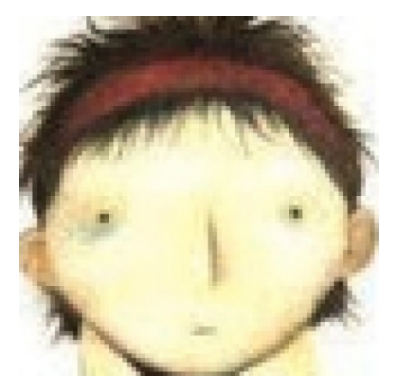

Figure 1: Aaron Swartz' profile picture on GitHub

It is unknown to us what its origins are, and what its meaning was to him.

He had also used it for his Twitter account, opened in March 2007 here too never to be changed again from what we can ascertain ${ }^{3}$.

He stayed on the platform from 2008 to 2013, the year of his death.

His last commit known to us occurred on January 6 2013, "2:40 PM UTC", and has for full signature :

f3c99f794a7f83f8e1645d4e58a89948a1939e65

This was 5 days before his death on January 11.

It pertained to his project htmldiff.

If Aaron had other GitHub accounts, or other similar ones on other sites, they are not known to us. This was his primary one by all we know.

Most likely he also created webpy ${ }^{4}$, with almost certitude pokayoke ${ }^{5}$, and possibly deaddrop ${ }^{6}$; though these were not personal but project accounts.

Let us give here some broad descriptions and trends of his activities :

2008 through 2010 were mostly concerned with his own two projects, watchdog and webpy, with the addition of tor 2 web at the end of 2010 .

2011 through 2013 marked a notable turn towards creating many more projects and contributing to many more outside of his own.

\footnotetext{
${ }^{1}$ https://github.com/aaronsw

${ }^{2}$ https://web.archive.org/web/20080510212557/https://github.com/aaronsw

${ }^{3}$ https://web.archive.org/web/20071031090837/https://twitter.com/aaronsw

${ }^{4}$ https://github.com/webpy

${ }^{5}$ https://github.com/pokayoke

${ }^{6}$ https://github.com/deaddrop
} 
All of these displayed a deep attachment to the web (of which webpy and html2text are perhaps the most important, or best known) and a lasting concern with how to use it for social change (watchdog).

Swartz' contributions to Tor have not been highlighted enough : he created or contributed to many programs for it, like tor 2 web.

Further analyses of the data presented here will no doubt provide many more insights into the life and work of this important figure, pioneer. 


\section{Data}

\subsection{Repositories and commits}

\begin{tabular}{|c|c|c|}
\hline \multicolumn{3}{|c|}{2008} \\
\hline April 4 & watchdog & created \\
\hline April & watchdog & 60 commits \\
\hline May & watchdog & 16 commits \\
\hline June & watchdog & 32 commits \\
\hline July & watchdog & 42 commits \\
\hline August & watchdog & 25 commits \\
\hline September & watchdog & 73 commits \\
\hline \multirow[t]{2}{*}{ October } & watchdog & 70 commits \\
\hline & webpy/webpy & 12 commits \\
\hline \multirow[t]{2}{*}{ November } & watchdog & 22 commits \\
\hline & webpy/webpy & 2 commits \\
\hline \multirow[t]{2}{*}{ December } & watchdog & 6 commits \\
\hline & webpy/webpy & 3 commits \\
\hline \multicolumn{3}{|c|}{2009} \\
\hline January & webpy/webpy & 1 commit \\
\hline February & watchdog & 5 commits \\
\hline March & webpy/webpy & 1 commit \\
\hline April & watchdog & 1 commit \\
\hline May - June & - & - \\
\hline July 30 & ghcontest & created \\
\hline \multirow[t]{3}{*}{ July } & ghcontest & 6 commits \\
\hline & watchdog & 3 commits \\
\hline & webpy/webpy & 3 commits \\
\hline August & watchdog & 16 commits \\
\hline September & - & - \\
\hline October & webpy/webpy & 1 commit \\
\hline November - December & - & - \\
\hline \multicolumn{3}{|c|}{2010} \\
\hline January - February & - & - \\
\hline March 27 & webpy & created \\
\hline April & webpy/webpy & 2 commits \\
\hline May - November & - & - \\
\hline December 25 & tor2web & created \\
\hline December 30 & tweepy & created \\
\hline \multirow[t]{2}{*}{ December } & webpy/webpy.org-old2 & 102 commits \\
\hline & tor 2 web & 13 commits \\
\hline
\end{tabular}

Table 1: Swartz' commits and repositories on GitHub (2008-2010). 


\begin{tabular}{|c|c|c|}
\hline \multicolumn{3}{|c|}{2011} \\
\hline January 26 & boto & created \\
\hline January 28 & html2text & created \\
\hline \multirow[t]{4}{*}{ January } & webpy/webpy.github.com & 70 commits \\
\hline & html2text & 3 commits \\
\hline & webpy/webpy & 3 commits \\
\hline & tor 2 web & 1 commit \\
\hline February 6 & rtask & created \\
\hline \multirow[t]{2}{*}{ February 19} & pytorctl & created \\
\hline & torperf & created \\
\hline \multirow[t]{7}{*}{ February } & torperf & 8 commits \\
\hline & html2text & 4 commits \\
\hline & pytorctl & 3 commits \\
\hline & rtask & 3 commits \\
\hline & tor2web & 1 commit \\
\hline & tweepy/tweepy & 1 commit \\
\hline & webpy/webpy & 1 commit \\
\hline March 4 & https-everywhere & created \\
\hline March 14 & python-transparencydata & created \\
\hline \multirow[t]{5}{*}{ March } & webpy/webpy & 2 commits \\
\hline & webpy/webpy.github.com & 2 commits \\
\hline & https-everywhere & 2 commits \\
\hline & sunlightlabs/python-transparencydata & 1 commit \\
\hline & html2text & 1 commit \\
\hline \multirow[t]{2}{*}{ April } & webpy/webpy.github.com & 5 commits \\
\hline & https-everywhere & 1 commit \\
\hline May & webpy/webpy.github.com & 7 commits \\
\hline \multirow[t]{3}{*}{ June } & naomifox/mass-email-delivery-code & 10 commits \\
\hline & webpy/webpy & 4 commits \\
\hline & webpy/webpy.github.com & 2 commits \\
\hline \multirow[t]{4}{*}{ July } & https-everywhere & 8 commits \\
\hline & naomifox/mass-email-delivery-code & 4 commits \\
\hline & webpy/webpy & 2 commits \\
\hline & webpy/webpy.github.com & 2 commits \\
\hline August 21 & chdns & created \\
\hline \multirow[t]{4}{*}{ August } & https-everywhere & 8 commits \\
\hline & tor2web & 4 commits \\
\hline & chdns & 1 commit \\
\hline & naomifox/mass-email-delivery-code & 1 commit \\
\hline \multicolumn{3}{|c|}{ (continued) } \\
\hline
\end{tabular}

Table 2: Swartz' commits and repositories on GitHub (2011-2013). 


\begin{tabular}{|c|c|c|}
\hline \multicolumn{3}{|c|}{2011 (continued) } \\
\hline September 20 & metamake & created \\
\hline \multirow{5}{*}{ September } & https-everywhere & 19 commits \\
\hline & html2text & 7 commits \\
\hline & metamake & 4 commits \\
\hline & webpy/webpy.github.com & 2 commits \\
\hline & webpy/webpy & 1 commit \\
\hline \multirow[t]{4}{*}{ October } & https-everywhere & 4 commits \\
\hline & html2text & 3 commits \\
\hline & webpy/webpy & 3 commits \\
\hline & webpy/webpy.github.com & 1 commit \\
\hline November 10 & opencongress & created \\
\hline \multirow[t]{3}{*}{ November } & html2text & 14 commits \\
\hline & webpy/webpy.github.com & 5 commits \\
\hline & https-everywhere & 1 commit \\
\hline December 21 & html2text-service & created \\
\hline December 27 & sanitize & created \\
\hline \multirow[t]{7}{*}{ December } & naomifox/mass-email-delivery-code & 17 commits \\
\hline & https-everywhere & 7 commits \\
\hline & sanitize & 4 commits \\
\hline & html2text & 3 commits \\
\hline & webpy/webpy & 2 commits \\
\hline & webpy/webpy.github.com & 2 commits \\
\hline & cv/html2text-service & 2 commits \\
\hline \multicolumn{3}{|c|}{2012} \\
\hline January 6 & jinja2 & created \\
\hline \multirow[t]{3}{*}{ January } & webpy/webpy.github.com & 4 commits \\
\hline & html2text & 4 commits \\
\hline & pallets/jinja & 2 commits \\
\hline February 27 & pybandit & created \\
\hline \multirow[t]{5}{*}{ February } & watchdog & 35 commits \\
\hline & webpy/webpy & 21 commits \\
\hline & infogami/infogami & 1 commit \\
\hline & pybandit & 1 commit \\
\hline & naomifox/mass-email-delivery-code & 1 commit \\
\hline \multirow[t]{4}{*}{ March } & webpy/webpy & 10 commits \\
\hline & webpy/webpy.github.com & 3 commits \\
\hline & tor2web & 2 commits \\
\hline & watchdog & 1 commit \\
\hline \multicolumn{3}{|c|}{ (continued) } \\
\hline
\end{tabular}

Table 3: Swartz' commits and repositories on GitHub (2011-2013). 


\begin{tabular}{|c|c|c|}
\hline \multicolumn{3}{|c|}{2012 (continued) } \\
\hline \multirow[t]{4}{*}{ April } & victorykit/victorykit & 37 commits \\
\hline & webpy/webpy.github.com & 3 commits \\
\hline & html2text & 1 commit \\
\hline & sanitize & 1 commit \\
\hline \multirow[t]{4}{*}{ May } & victorykit/victorykit & 101 commits \\
\hline & html2text & 2 commits \\
\hline & webpy/webpy.github.com & 2 commits \\
\hline & webpy/webpy & 1 commit \\
\hline June 25 & aaronsw.github.com & created \\
\hline \multirow[t]{3}{*}{ June } & pokayoke/pokayoke.github.com & 19 commits \\
\hline & victorykit/victorykit & 17 commits \\
\hline & aaronsw.github.com & 1 commit \\
\hline July 4 & $t r y-g i t$ & created \\
\hline \multirow[t]{5}{*}{ July } & victorykit/victorykit & 39 commits \\
\hline & html2text & 2 commits \\
\hline & webpy/webpy.github.com & 1 commit \\
\hline & tor 2 web & 1 commit \\
\hline & pokayoke/pokayoke.github.com & 1 commit \\
\hline August 7 & pusher_client_python & created \\
\hline \multirow[t]{2}{*}{ August 28} & commentsareclosed & created \\
\hline & commitron & created \\
\hline \multirow[t]{7}{*}{ August } & victorykit/victorykit & 35 commits \\
\hline & victorykit/dudley & 27 commits \\
\hline & webpy/webpy.github.com & 9 commits \\
\hline & webpy/webpy & 5 commits \\
\hline & commentsareclosed & 2 commits \\
\hline & victorykit/commitron & 1 commit \\
\hline & pusher/pusher-http-python & 1 commit \\
\hline \multirow[t]{7}{*}{ September } & victorykit/dudley & 22 commits \\
\hline & victorykit/victorykit & 22 commits \\
\hline & html2text & 6 commits \\
\hline & victorykit/whiplash & 5 commits \\
\hline & webpy/webpy.github.com & 1 commit \\
\hline & webpy/webpy & 1 commit \\
\hline & commentsareclosed & 1 commit \\
\hline \multirow[t]{5}{*}{ October } & victorykit/victorykit & 80 commits \\
\hline & html2text & 4 commits \\
\hline & webpy/webpy & 2 commits \\
\hline & victorykit/dudley & 2 commits \\
\hline & victorykit/whiplash & 1 commit \\
\hline
\end{tabular}

Table 4: Swartz' commits and repositories on GitHub (2011-2013). 


\begin{tabular}{|l|c|r|}
\hline \multicolumn{3}{|c|}{2012 (continued) } \\
\hline November 1 & cube-client & created \\
\hline November & victorykit/victorykit & 28 commits \\
\hline & html2text & 6 commits \\
\hline & tsileo/cube-client & 2 commits \\
\hline & naomifox/mass-email-delivery-code & 2 commits \\
\hline & webpy/webpy & 1 commit \\
\hline & webpy/webpy.github.com & 1 commit \\
\hline December & webpy/webpy & 3 commits \\
\hline & $\mathbf{2 0 1 3}$ & 1 commit \\
\hline & htmldiff & created \\
\hline January 5 & jsonformat & 3 commits \\
\hline & htmldiff & 1 commit \\
\hline January & voxelbrain/jsonformat & 1 commit \\
\hline
\end{tabular}

Table 5: Swartz' commits and repositories on GitHub (2011-2013).

A note about the conventions adopted here : projects (or repositories) created by Aaron Swartz on his account are not prefixed by an additional account name. This is in opposition to projects that he contributed to but either had not been created by him, or on his account, like webpy.

We use the symbol - to indicate no activity (and thus no projects).

Blanks below dates or months explicitly mean that it is repeated. 


\subsection{Projects and descriptions}

\begin{tabular}{|c|c|c|}
\hline Project & Created & GitHub description \\
\hline watchdog & Apr 2008 & The watchdog project. http://watchdog.net/ \\
\hline ghcontest & Jul 2009 & contest.github entry http://contest.github.com/ \\
\hline webpy (f) & Mar 2010 & $\begin{array}{l}\text { web.py is a web framework for python that is as sim- } \\
\text { ple as it is powerful. }\end{array}$ \\
\hline tor2web & Dec 2010 & $\begin{array}{l}\text { access tor hidden services thru the Web } \\
\text { http://tor2web.org/ }\end{array}$ \\
\hline tweepy (f) & Dec 2010 & $\begin{array}{l}\text { A python library for the Twitter API. OAuth, com- } \\
\text { plete coverage, streaming API }\end{array}$ \\
\hline boto $(\mathrm{f})$ & Jan 2011 & $\begin{array}{l}\text { Python interface to Amazon Web Services } \\
\text { http://boto.cloudhackers.com/ }\end{array}$ \\
\hline html2text & Jan 2011 & Convert HTML to Markdown-formatted text. \\
\hline rtask & Feb 2011 & \\
\hline pytorctl & Feb 2011 & \\
\hline torperf & Feb 2011 & \\
\hline https-everywhere & Mar 2011 & HTTPS Everywhere \\
\hline python-transparencydata (f) & Mar 2011 & Wrapper for TransparencyData.com API \\
\hline chdns & Aug 2011 & Consistent hashing based DNS \\
\hline metamake & Sep 2011 & simple make-based weblog platform \\
\hline opencongress (f) & Nov 2011 & Open Congress \\
\hline html2text-service (f) & Dec 2011 & $\begin{array}{l}\text { A RESTful service to convert } \\
\text { Markdown-like text }\end{array}$ \\
\hline sanitize & Dec 2011 & bringing sanity to world of messed-up data \\
\hline jinja2 (f) & Jan 2012 & The Jinja2 template engine \\
\hline pybandit & Feb 2012 & Python experiments in bandit algorithms \\
\hline aaronsw.github.com & Jun 2012 & \\
\hline try_git & July 2012 & \\
\hline pusher_client_python (f) & Aug 2012 & $\begin{array}{l}\text { Python lib for adding Pusher support into your ap- } \\
\text { plication }\end{array}$ \\
\hline commentsareclosed & Aug 2012 & \\
\hline commitron (f) & Aug 2012 & $\begin{array}{l}\text { Monitor Github and RailsOnFire for commits and } \\
\text { build status and update Skype. }\end{array}$ \\
\hline cube-client (f) & Nov 2012 & $\begin{array}{l}\text { A Python client for Cube: Time Series Data Collec- } \\
\text { tion \& Analysis }\end{array}$ \\
\hline htmldiff & Jan 2013 & Highlights the differences between two HTML pages. \\
\hline jsonformat (f) & Jan 2013 & \\
\hline
\end{tabular}

Table 6: Swartz' repositories and their descriptions, with dates.

Many of these projects are so-called "forks", this is to say copies of pre-existing projects (some well known, like jinja2, others less so). We signal this here accordingly with the apposition of the symbol (f). 
With other projects it is more complicated.

In the case of https-everywhere, this is "the Chrome port" of the same software ${ }^{7}$. While webpy and pokayoke are forks of his own projects.

rtask is a mysterious little program with no description or documentation we could find. Commit comments hold "first night's work".

\subsection{Languages and licenses}

\begin{tabular}{|l|c|r|}
\hline Project & Language (main) & License \\
\hline watchdog & Python & AGPL-3.0 \\
\hline ghcontest & Python & Public domain \\
\hline webpy & Python & AGPL-3.0 \\
\hline tor2web & CSS & \\
\hline html2text & Python & Custom (inherited) \\
\hline rtask & Python & \\
\hline pytorctl & Python & \\
\hline torperf & C & BSD-3-Clause (inherited) \\
\hline https-everywhere & JavaScript & \\
\hline chdns & Python & \\
\hline metamake & Python & \\
\hline sanitize & Python & BSD-2-Clause (inherited) \\
\hline pybandit & Python & \\
\hline aaronsw.github.com & & \\
\hline try_git & & \\
\hline commentsareclosed & Python & \\
\hline
\end{tabular}

Table 7: Swartz' projects (non-forks) : languages and licenses.

When Aaron was free to choose licenses without restrictions, he picked either the Public Domain (this is true for his early projects in particular, webpy falls under this category) or the GNU AGPL v3 license (chosen for all of his later major projects e.g. html2text ${ }^{8}$ ).

Whenever he was free to choose a language, he consistently picked Python.

While none of these projects are marked as forks on GitHub, some of them appear to be nonetheless (i.e. they come from other sources than GitHub itself).

This includes sanitize whose README file holds :

sanitize (...) was originally written by Mark Pilgrim and is distributed under the BSD license.

\footnotetext{
${ }^{7}$ Based on the information provided by Peter Eckersley in an article published the day after Swartz' death on the EFF website.

${ }^{8}$ For ghcontest, he picked the Public domain license (again), which may have been due to the particularities of this contest.
} 
For this project a BSD license was used that - according to this text - has been inherited from the original author.

torperf also appears to be a fork from elsewhere, with the same conditions.

The secondary languages of tor 2 web are Python and Javascript (in order). Those of torperf Python and R. 


\section{Qualitative analysis}

During 2008 Aaron Swartz created a single repository, watchdog, and continued to contribute to his pre-existing project webpy (at the eponymous account webpy).

His first 6 months on the platform, from April to September 2008, were entirely dedicated to watchdog ("the watchdog project" per its description). He committed to no other project.

What was the watchdog project? In the earliest (recorded) version of its website it was presented like so :

We're trying to build a hub for politics on the Internet. Our plan has three parts: [data, action, causes] ${ }^{9}$

While Aaron's presentation read

Founder Aaron Swartz has been building web applications for far too long. He co-founded Reddit (since purchased by Conde Nast), Jottit, Open Library, and theinfo.org. His writing on technology and politics has appeared in Extra!, Wired, Personal Democracy Forum, and other publications. ${ }^{10}$

His collaborators were Pradeep Gowda (listed as programmer), Kragen Sitaker (programmer) and Nathan Borror (designer).

Starting with October 2008, he began to contribute to webpy; and from October to December of that same year committed to both, while watchdog remained his priority (based on the number of commits ${ }^{11}$ ).

From January to April 2009, he alternated between both projects, with watchdog still a priority.

Between May and June of 2009 came a first period of inactivity since opening his account.

In September 2009 came another.

To explain these, we draw on other data and archives.

His inactivity on GitHub may be explained by the fact that in that same month of September he had been very active on his blog, Raw Thought, producing some of his best known and longest posts. They include among others : "On Finishing Infinite Jest" (September 16), "A Summary/Explanation of John Maynard Keynes' General Theory" (September 22), and "Keynes, Explained Briefly" (September 24). ${ }^{12}$

Needless to say, these are both large books.

\footnotetext{
${ }^{9}$ https://web.archive.org/web/20080420071534/http://watchdog.net/about/

${ }^{10}$ Ibid.

${ }^{11}$ It should be noted that this is an imperfect indicator, as 1 large commit may hold more changes than 10 small ones; to say nothing of hard to measure facts such as the respective difficulties of each task.

12 "Why I Am Not Gay" (September 8). A post not unrelated to Keynes, who had and was married to a woman - to much surprise from his entourage - but had mostly had relationships with men; a problem of classification for modern categories. This is exactly the nature and content of this post, where Aaron tells openly about enjoying "hookups" with men and women alike.
} 
So those are Keynes' prescriptions for a successful economy: low interest rates, government investment, and redistribution to the poor. And, for a time - from around the 1940s to the 1970 s - that's kind of what we did. (...)

But, starting in the 1970 s, the rich staged a counterattack. They didn't like watching inequality - and their wealth - melt away. There was a resurgence in classical economics, Keynes was declared to have been debunked

That month he published over 10 posts (compare with 4 in October, 3 in November, and 3 in December).

On July 302009 he created his second repository, entitled ghcontest, to participate in the GitHub Contest of that year.

His entry scored 990, placing him about in the middle of contestants. The best entry scored $2725 .{ }^{1314}$

History, this we cannot repeat or stress enough, fulfills an important role in that it helps us break with doubtful notions - a-temporal and asociological - such as those of "genius"; to say nothing of modern ones like "rock stars" that are the dismal products of an even more dismal industry.

But, it should come also as no surprise that members of those same communities have little to no affection or esteem for the humanities.

This is even more so as these same sciences represent one of the first and last sources of critic of them. One could look long, but always in vain towards computer science for answers that matter.

So Paul Graham, who knows nothing of them, which has not hindered him to speak with the assurance that only belongs to those who have the sad benefit of ignorance.

The social sciences are also fairly bogus, because they're so much influenced by intellectual fashions. ${ }^{15}$

- wrote this half-wit. From the social sciences he excludes history, doubly asserting his lack of knowledge of both, ignorant of current developments in both : as such he will know the benefit of being reminded of his own, and that of his "milieu", like a historian of science wrote. ${ }^{16}$

From May to November 2010 came Aaron Swartz' longest period of inactivity.

In May he also was inactive on Raw Thought. What happened then? We don't know, but leave this as a note for others, to explore further.

We think he may have been working on tor2web, but not publicly.

In a December 2010 post he published "A Censorship-Resistant Web" (December 21) in which Tor and tor2web are mentioned; coinciding with

\footnotetext{
${ }^{13}$ https://web.archive.org/web/20091202045539/http://contest.github.com/

${ }^{14}$ https://web.archive.org/web/20091202085144/http://contest.github.com/leaderboard ${ }^{15}$ Graham 2005

${ }^{16}$ Almost all major historians have been influenced by the social sciences, since the days of Bloch and Febvre at least, for the real (and selfish) reason that their advantages to them were, and proved simply too big to ignore.
} 
the release of the software the same month (preceding it by 4 days to be exact).

Step four: Beyond the Web

We can help ensure this by operating at least one of each as a Tor hidden service. Because the operator of the service is anonymous, they are immune to legal threats. If the user doesn't have Tor, they can access them through tor2web.org.

Correlation with his blog activities on Raw Thought however is not infallible, and not enough. Other sources should be considered ${ }^{17}$.

On December 252010 came his third project : tor2web.

According to the information provided by GitHub, this was "Built by@aaronsw@ioerror"; ioerror being the account of, and pseudonym commonly used by Jacob Applebaum.

Two commits associated with him occurred on that same day :

dbaed82ac729c8ed3a602bbdf8cd3f75f52edf1a (12:20 AM UTC)

8dd59489e8de3ce2659d7326262be797b5fe415f (2:06 AM UTC)

While the website for this project itself holds :

tor2web.org is a disruptive website brought to you by Virgil Griffith and Aaron Swartz ${ }^{18}$

So far, this project's history and narrative has not included Applebaum. We leave this, too, as a note and reminder that further research is necessary.

Starting June 2011 he took an interest in a program called mass-email-delivery-code by Naomi Fox, and regularly contributed to it henceforth.

2012 marked a return to the watchdog project with 35 commits in February, abandoned for a while. And, again in the following month of March : 1 commit.

Another notable event of February was a commit to infogami/infogami (his old start-up)! A minor fix.

Starting mid-2012, he took an interest in victorykit (a platform "for social change" per its description) and made hundreds of commits towards it.

On June 2012 he started contributing to pokayoke/pokayoke.github.com, his own project. Traces and echoes of it can be found in his blog, in an entry published around the same time :

I've put together a new guide for developing software, from idea to architectural details. The idea was to combine all the good ideas I'd heard from various areas of software development into a single, concise document. (...)

The Pokayoke Guide to Developing Software

I'm eager for suggestions and feedback. ${ }^{19}$

\footnotetext{
${ }^{17}$ His Twitter account among others.

${ }^{18}$ https://web.archive.org/web/20090124070150/https://tor2web.org/

19 "New: The Pokayoke Guide to Developing Software" (June 26, 2012).
} 
A further analysis of this now compiled data will no doubt result in hitherto unexpected, unsuspected, unknown or underestimated information.

\section{Word of caution}

This does not represent a full picture of Aaron Swartz' activity on GitHub. Since his death, this platform has changed considerably, and many projects too (some deleted, or modified in some other major way).

For instance, his contributions to DeadDrop cannot be found in this list, as they likewise cannot be found on his Github page currently, and neither - all is linked - on the Github page of the project ${ }^{20}$.

Only a search through archive.org may enable the recovery of some of these 'lost contributions'.

Presumably other of his contributions are affected. Perhaps many - it is hard to say, and an in-depth research would be needed.

Finally, what this research offers no window into is how funny and quirky Aaron Swartz was at times, or simple at others. Here are two examples among many found in the thousands of lines of code that he wrote :

Through copious research I have discovered that purple is not really a color. Call Dan Rather!

and elsewhere :

couple bugfixes

\section{Conclusion - outward causes turned in- ward}

Aaron Swartz' life on GitHub reveals strangely intimate details about his life. - not so surprisingly to those who are accustomed to these platforms. They do in fact reveal intimate patterns, and habits.

They may and will no doubt provide much and unexpected information into other facets of his life. This we strongly expect.

Any biographer not doing a thorough review of such data, that are archives in the most classical sense, cannot pretend to exhaustion of sources.

It tells for instance about holidays taken, holidays observed (Christmas for instance), etc.

In 2008, for instance, Swartz' last commit was on Dec 16, 2008 (c8d5...); to resume only on 27 th of January of the next year $(2324 \ldots)$.

His biggest period of inactivity came in 2010, no activity from May to November of that year (except for 1 issue created for tweepy/tweepy).

${ }^{20}$ https://github.com/deaddrop 
What other projects did he work on during this time? Or did he prefer working on these projects locally before making them public (like tor2web, which suddenly makes an appearance on the 25th of December of that year)?

It may also help, either confirm or disprove, previous testimonies given about him.

His former partner Taren Stinebrickner-Kauffman wrote :

over the last 20 months of his life, Aaron spent more time with me than with anyone else in the world. For much of the last 8 months of his life, we lived together, commuted together, and worked in the same office - and I was never worried he was depressed until the last 24 hours of his life. ${ }^{21}$

This is in our opinion consistent with our data and findings.

To provide even more context for this : his last Twitter post was on January 8 ("5:03 $P M ")^{22}$,

Aaron Swartz@aaronsw.8 Jan 2013

Philip Diehl, the most respected U.S. Mint director America's ever had, joins the campaign to \#mintthecoin:

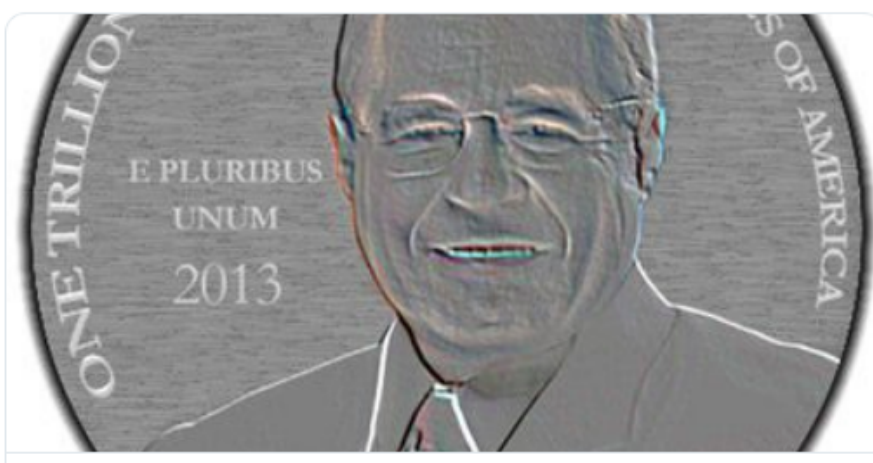

A trillion-dollar-coin idea takes off, and a former head of the U.S. Mi...

Rep. Jerry Nadler proposed issuing a trillion-dollar coin to circumvent an impending fight over the federal debt ceiling, and the idea has taken off. politico.com

$44 \quad$ ¿ $111 \quad \bigcirc \quad 156$

Figure 2: Aaron Swartz' Twitter account

His last blog entry that we could find was on November 1, "What Happens in The Dark Knight" :

\footnotetext{
${ }^{21}$ Stinebrickner-Kauffman 2013.

${ }^{22}$ https://twitter.com/aaronsw/status/288813125401186304
} 
As weve discussed, in Batman Begins 1960s-style full employment and antipoverty programs lead to skyrocketing crime while in The Dark Knight Rises 1980s-style tough-on-crime policies and neoliberal economics lead to a revolt of the economic underclass. The films are mirror images, one about the failure of liberal policies; the other about the failure of conservative policies.

Depression is commonly described as being associated with the loss of interest in previous (and previously enjoyed) hobbies.

From the archives we draw on here, his activities on GitHub, and others, no such thing can be said, and no such signs are found.

Aaron Swartz continued to program on a regular basis, up to his very last few days. - as attested again by his recorded online GitHub activities.

It is not consistent with other hypothesis such as for example that of a suicide linked to depression as surmised by some ${ }^{23}$.

In fact, as we have shown, and as can now be verified, the periods years and months - right before had been amongst his most productive.

These analyses, like those of perhaps the entire psychological profession, turn outward causes inwards; and mistake the social and sociological root causes of behaviors for what they are not : not a coincidence but a cause.

Economics was once called famously "the dismal science". But, as for psychology and psychiatry, these doubtful disciplines of a most nefarious, cruel history, they are our abysmal sciences...

Instead of looking inside, their zealous door-to-door sellers may wish to look outside, and at the wider outside world; in which they would discover their true place : the 'very bottom members of our society'.

In this outside world, in which we live, in the "real world" thus, Aaron Swartz had been victim of a society that mistook its heroes for its villains, and celebrates it villains as its heroes. - it too.

"And, here I thought it was the peanuts that attracted the morally ambiguous crowd." Aaron would have understood, who had never belonged to the latter category.

He paid the price, and this is why papers and articles are written about him, and not them (except to damn them).

${ }^{23}$ Publications like The Atlantic for instance. 


\section{Bibliography}

—. 2019. "The lonely death of Aaron, the cowards at MIT."

Davenport-Hines, Richard. 2015. Universal Man: The Lives of John

Maynard Keynes. Basic Books.

Eckersley, Peter. 2013. "Farewell to Aaron Swartz, an Extraordinary

Hacker and Activist". January 12.

https://www.eff.org/deeplinks/2013/01/farewell-aaron-swartz

Graham, Paul. 2005. "Undergraduation". March. http://www.paulgraham.com/college.html

Swartz, Aaron. 2008-2013. https://github.com/aaronsw

—. 2005-2012. http://www.aaronsw.com/weblog/fullarchive

—. 2007-2013. https://twitter.com/aaronsw

Stinebrickner-Kauffman, Taren. 2013. "Why Aaron died". February 4.

https://tarensk.tumblr.com/post/42260548767/why-aaron-died

Whedon, Joss. 1999-2004. Angel. 